\title{
Hammond Hill Research Catchment: Supporting Hydrologic Investigations of Rooting Zone and Vegetation Water Dynamics under Climate Change
}

\author{
James Knighton ${ }^{1}$, Kanishka Singh ${ }^{1}$, Valessa Souter-Kline ${ }^{2}$, and Todd Walter ${ }^{3}$ \\ ${ }^{1}$ Cornell University \\ ${ }^{2}$ Invenergy. LLC. \\ ${ }^{3}$ Cornell
}

May 11, 2020

\begin{abstract}
The Hammond Hill Research Catchment (HH) is a small (120 ha), temperate, second order tributary to Six Mile Creek, Cayuga Lake, and the Great Lakes $\left(42.42^{\circ},-76.32^{\circ}\right)$. The HH has been monitored since January 2017 for the purpose of understanding how recent infiltration mixes with antecedent soil water on hillslope forest floors and the spatial and temporal patterns of Root Water Uptake (RWU) by temperate northeastern US tree species (eastern hemlock [Tsuga canadensis], American beech [Fagus grandifolia], and sugar maple [Acer saccharum]). These data are informing us about the hydrologic consequences of anticipated tree species composition change and supporting the development of more refined ecohydrological models. The glaciated catchment is underlain by a shallow confining siltstone layer $(1-1.5 \mathrm{~m}$ depth) and dense with a regrowth (approximately 60 years old) mixed species forest of hemlock, beech, and other deciduous tree species common to the northeastern US. Current datasets from the HH include fixed-internal precipitation snow water equivalent, and discharge, and associated isotopic water compositions $(2 \mathrm{H} \& 18 \mathrm{O})$. Frequent ( $<1$ month) measurements of shallow (top $10 \mathrm{~cm}$ ) soil water content and bulk soil water and hemlock and beech xylem isotopic compositions are made at six locations across a topographic wetness gradient. The near-term role of the $\mathrm{HH}$ is to support an understanding of the environmental and ecological drivers of plant RWU competition and ecohydrologic education.
\end{abstract}

Hammond Hill Research Catchment: Supporting Hydrologic Investigations of Rooting Zone and Vegetation Water Dynamics under Climate Change

James Knighton $^{1}$, Kanishka Singh ${ }^{2}$, Valessa Souter-Kline ${ }^{3}$, M. Todd Walter ${ }^{4}$

${ }^{1}$ University of Connecticut, Department of Natural Resources and the Environment, Storrs, CT US

${ }^{2,4}$ Cornell University, Department of Biological and Environmental Engineering, Ithaca, NY US

${ }^{3}$ Invenergy, LLC., Annapolis, MD

1 Corresponding Author : james.knighton@uconn.edu; Phone: 1-215-317-0980; Mailing Address: 1376 Storrs Road, Unit 4087, Storrs, CT 06269-4087

2 ks983@cornell.edu

3 vsouterkline@gmail.com

4 mtw5@cornell.edu 
Abstract : The Hammond Hill Research Catchment (HH) is a small (120 ha), temperate, second order tributary to Six Mile Creek, Cayuga Lake, and the Great Lakes $\left(42.42^{\circ},-76.32^{\circ}\right)$. The HH has been monitored since January 2017 for the purpose of understanding how recent infiltration mixes with antecedent soil water on hillslope forest floors and the spatial and temporal patterns of Root Water Uptake (RWU) by temperate northeastern US tree species (eastern hemlock [Tsuga canadensis], American beech [Fagus grandifolia ], and sugar maple [Acer saccharum ]). These data are informing us about the hydrologic consequences of anticipated tree species composition change and supporting the development of more refined ecohydrological models. The glaciated catchment is underlain by a shallow confining siltstone layer $(1-1.5 \mathrm{~m}$ depth $)$ and dense with a regrowth (approximately 60 years old) mixed species forest of hemlock, beech, and other deciduous tree species common to the northeastern US. Current datasets from the HH include precipitation snow water equivalent, and discharge, and associated isotopic water compositions $\left({ }^{2} \mathrm{H} \&{ }^{18} \mathrm{O}\right)$. Frequent $(<1$ month) measurements of shallow (top $10 \mathrm{~cm})$ soil water content and bulk soil water and hemlock and beech xylem isotopic compositions are made at several locations across a topographic wetness gradient. The near-term role of the $\mathrm{HH}$ is to support an understanding of the environmental and ecological drivers of plant RWU competition and hydrologic education.

Keywords : research catchment, ecohydrology, stable isotopes, instrumentation, hydrologic modeling

The Hammond Hill Research Catchment (HH; Fig. 1) is 120 hectare, temperate, intermittent catchment, located in central New York, US $\left(42.42^{\circ},-76.32^{\circ}\right)$. The catchment has been monitored since 2017 for the purpose of understanding how hydrologic conditions will respond to warming air temperatures, changing precipitation patterns, and shifting forest ecology. Hydrologic observations within HH have helped us understand: how changes in forest tree composition could influence discharge regimes across the Northeast US (Knighton et al., 2019a), how ephemeral periods of thawing soils and snowmelt in spring might accelerate "old" soil water through the HH critical zone (Knighton et al., 2019b), and how we can better represent above-ground tree-water storage in ecohydrologic models (Knighton et al., 2019b; 2020).

The $\mathrm{HH}$ exists in a temperate climate and ranges in elevation from 390 to $590 \mathrm{~m}$ above mean sea level. Freezing air temperatures have generally persisted from December through May, with an average maximum snowpack accumulation of $50 \mathrm{~mm}$ (Fig. 2a). Annual precipitation is approximately $1200 \mathrm{~mm}$ per year, with $20 \%$ contributing to the winter snowpack. Annual daily precipitation extremes typically occur in late summer and fall (Fig. 2c, d) via local convective precipitation events and regional tropical moisture derived rainfall (Knighton et al., 2017). Catchment discharge extremes are bi-modal with high flow events in the spring (Fig. 2b) and fall (Fig. 2d) occurring from rain-on-snow and tropical moisture precipitation, respectively.

The HH exists within the glaciated region of the New York, US. Catchment soils are Cambisols with a relatively shallow depth to the siltstone bedrock parent material, ranging from 1 to $1.5 \mathrm{~m}$. At upslope locations, soils have a $5 \mathrm{~cm}$ organic layer ( $~ 70 \%$ mass loss on ignition). The gravel content of mineral soils is $0-22 \%$ by mass at the surface, and $38-71 \%$ at $30 \mathrm{~cm}$ depth. Highly weathered bedrock is encountered at roughly $50 \mathrm{~cm}$ depth. At upslope locations, recent precipitation bypasses soils in winter and summer as preferential flow (Knighton et al 2019b), in agreement with recent observations of limited mixing across soil water tensions at other long term research catchments (e.g. Sprenger et al., 2019). During the period of spring snowmelt and fall soil rewetting, recent infiltration was found to mix with and displace older soil water, similar to observations in boreal regions (Alo-Aho et al., 2018).

The HH canopy is a mixture of the coniferous Eastern hemlock (Tsuga canadensis ) and deciduous American beech (Fagus grandifolia), basswood (Tilia Americana), northern red oak (Quercus rubra), red maple (Acer rubrum ), sugar maple (Acer saccharum ). Understory trees and shrubs include American hophornbeam (Ostrya virginiana), American beech, American hornbream (Carpinus caroliniana), bigtooth aspen (Populus grandidentata), black birch (Betula lenta), cucumber tree (Magnolia acuminata), eastern white pine (Pinus strobus), mountain camellia (Stewartia ovata), striped maple (Acer pensylvanicum), tulip poplar (Liriodendron tulipifera), and white ash (Fraxinus americana), as well as various ferns and grasses. Hemlock and beech are the dominant tree species with densities of $0.31 \mathrm{~m}^{-2}$ and $0.12 \mathrm{~m}^{-2}$ respectively. 
Eastern hemlock trees are regionally threatened by the hemlock wooly adelgid (Adelges tsugae), an invasive insect. Measurements of isotopes in soils and xylem in the HH (Fig. 3) and hydrologic modeling suggest that forest species composition change following a loss of hemlock and succession by hardwood tree species (e.g. beech) could lead to a drastically altered hydrologic state, characterized by reduced summer transpiration, increased groundwater storage, and elevated discharge extremes (Knighton et al., 2019a). Regional observations of hemlock loss have yielded similar conclusions (e.g. Kim et al 2017; Singh et al., 2020) indicating that continued monitoring is necessary to better understand the future hazards.

Datasets available for the $\mathrm{HH}$ comprise meteorological, hydrological, and ecohydrological measurements (Knighton et al., 2019c). Precipitation is measured at a 15-minute interval with a tipping bucket rain gage $1 \mathrm{~km}$ from the catchment outlet in an open field. Air temperatures and pressures are measured near the catchment outlet with a pressure transducer. Stream depth is recorded at a 10-minute interval with a pressure transducer. A rating curve is established for the catchment outlet. Precipitation, stream water, canopy throughfall, and snowpack samples have been collected for isotopic analysis since January 2017. Across a gradient of topographic wetness, shallow (top $12 \mathrm{~cm}$ ) soil moisture and bulk soil water isotopic compositions were measured weekly from January 2017 to January 2018. Hemlock and beech stems and bulk soil water depth profiles were collected in August 2017, November 2017, and June 2018. Stem samples were suberized stems clipped near the trunk, approximately $1 \mathrm{~m}$ from any green leaves.

In July 2019, a set of paired field-sites were established within the catchment, with the forest cover of one site dominated by co-habiting Eastern hemlock, American beech and Sugar maple, and that of the other site comprised primarily by co-habiting American beech and Sugar maple but lacking any hemlock specimens. The difference in tree species composition between sites captures the rooting schemes and hydraulic properties of Sugar maple and American beech in both the presence and absence of Eastern hemlock, thereby allowing us to examine to what extent the presence of a single foundation species influences the water use strategies of cohabiting species, and further adumbrates the root-level adjustments of candidate successors following Eastern hemlock loss. Soil and tree cores have been retrieved monthly at both sites for isotopic analysis since August 2019, with an interruption from December 2019 until March 2020. Volumetric water content has been recorded at a 30-minute fixed interval at the site featuring hemlock using capacitance/frequency domain sensors buried at four soil depths. Soil moisture has also been measured during monthly sampling campaigns at the same four depths at both sites using a handheld soil moisture sensor. In April 2020, thermal dissipation probes were installed at the hemlock site, operating with the aid of a $90 \mathrm{~W}$ solar panel and deep cycle battery, to determine sap flow through hemlock, beech, and maple at 10-minute intervals.

All stem, tree cores, and soil samples were extracted via cryogenic vacuum extraction with a maximum pressure of $10 \mathrm{kPa}$, a minimum extraction time of 180 minutes, and a temperature differential of $296{ }^{\circ} \mathrm{C}$. Soil and xylem water samples were analyzed via a Los Gatos Research Off-Axis Integrated Cavity Output Spectroscopy. Precipitation, throughfall (one location), stream, and snow samples were analyzed on a Thermo Delta V isotope ratio mass spectrometer interfaced to a Gas Bench II.

\section{Data Availability Statement}

Data for the $\mathrm{HH}$ is available at Knighton et al. (2019c) in the CUAHSI HydroClient database (https://data.cuahsi.org/) under the project CUISO. Hydrologic data may be accessed via the map application (latitude $42.42^{\circ}$, longitude $-76.32 \mathrm{deg}$ ).

\section{References}

Ala-Aho, P., Soulsby, C., Pokrovsky, O. S., Kirpotin, S. N., Karlsson, J., Serikova, S., ... \& Tetzlaff, D. (2018). Using stable isotopes to assess surface water source dynamics and hydrological connectivity in a high-latitude wetland and permafrost influenced landscape. Journal of Hydrology, 556, 279-293.

Knighton J., Steinschneider, S., Walter, M.T. (2017). A Vulnerability-Based, Bottom-Up Assessment of Future Riverine Flood Risk Using a Modified Peaks-over-Threshold Approach and a Physically Based Hydrologic Model. Water Resources Research. DOI: 10.1002/2017WR021036 
Knighton J., Coneelly, J., Walter, M. (2019a). Possible Increases in Flood Frequency Due to the Loss of Eastern Hemlock in the Northeastern US: Observational Insights and Predicted Impacts. Water Resources Research. DOI: 10.1029/2018WR024395

Knighton J., Souter-Kline, V., Volkmann, T., Troch, P., Kim, M., Harman, C., Morris, C., Buchanan, B., Walter, M.T. (2019b). Spatial and Topographic Variations in Ecohydrologic Separation in a Small, Temperate, Snow-Influenced Catchment. Water Resources Research. DOI:10.1029/2019WR025174

Knighton, J. (2019c). CUISO: Cornell Six Mile Creek Isotopes. CUAHSI HydroClient. DOI: 10.4211/his5651

Knighton J., Kuppel, S., Smith, A., Sprenger, M., Soulsby, C., Tetzlaff, D. (In Press). Using Isotopes to Incorporate Tree Water Storage and Mixing Dynamics into a Distributed Ecohydrologic Modelling Framework. Ecohydrology. DOI: 10.1002/eco.2201

Singh, K., Knighton, J., Whitmore, M., Walter, M.T., Lassoie, J.P. (2020). Simulation and statistical modeling approaches to investigate hydrologic regime transformations following Eastern hemlock decline. Hydrological Processes.

Sprenger, M., Tetzlaff, D., Buttle, J., Carey, S. K., McNamara, J. P., Laudon, H., .. \& \& Soulsby, C. (2018). Storage, mixing, and fluxes of water in the critical zone across northern environments inferred by stable isotopes of soil water. Hydrological processes, 32(12), 1720-1737.

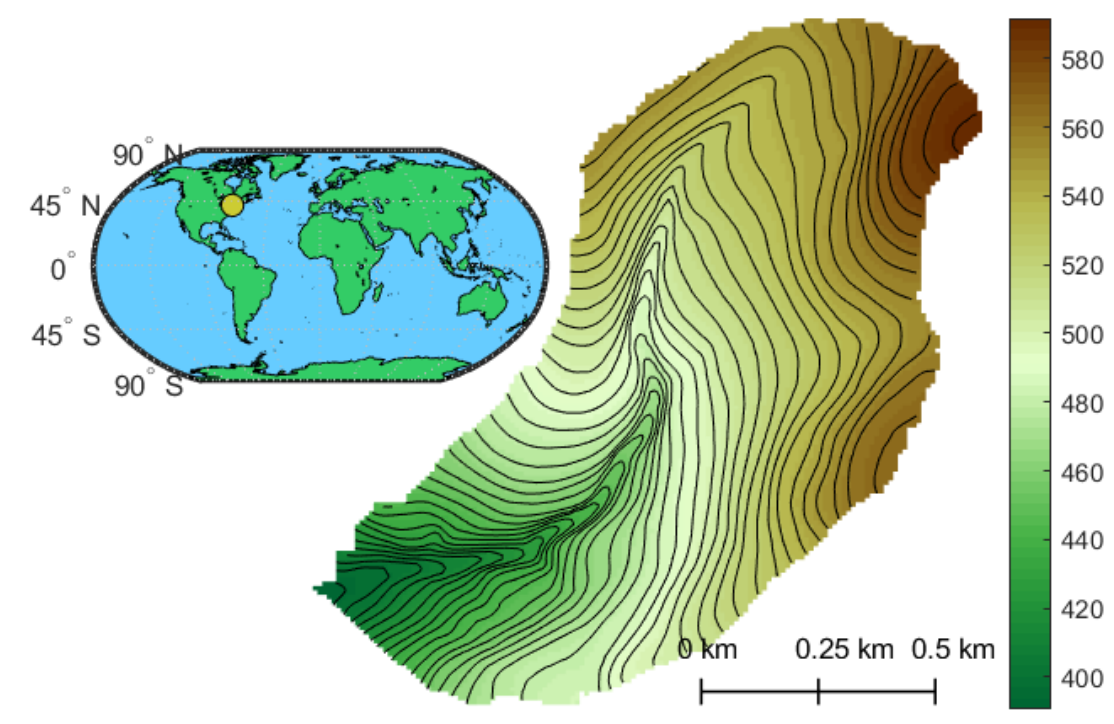

Figure 1 -Hammond Hill Research Catchment global overview and digital elevation map. 


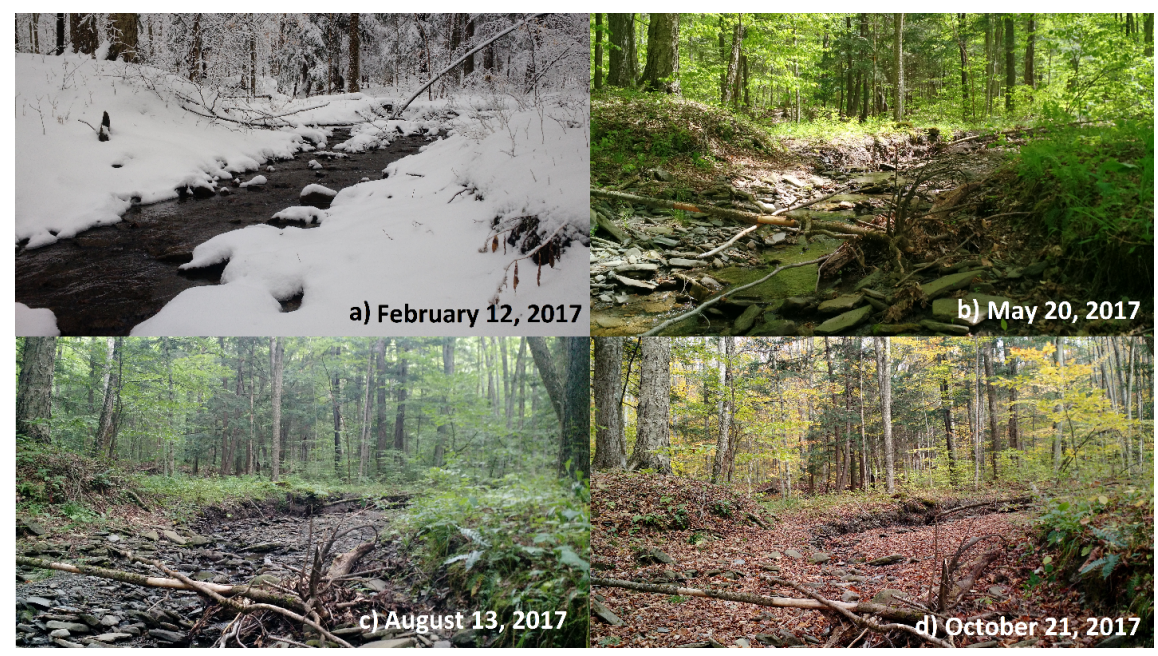

Figure 2 -Photographs taken at the Hammond Hill Research Catchment outlet facing upstream in the a) winter, b) spring, c) summer, and d) fall.
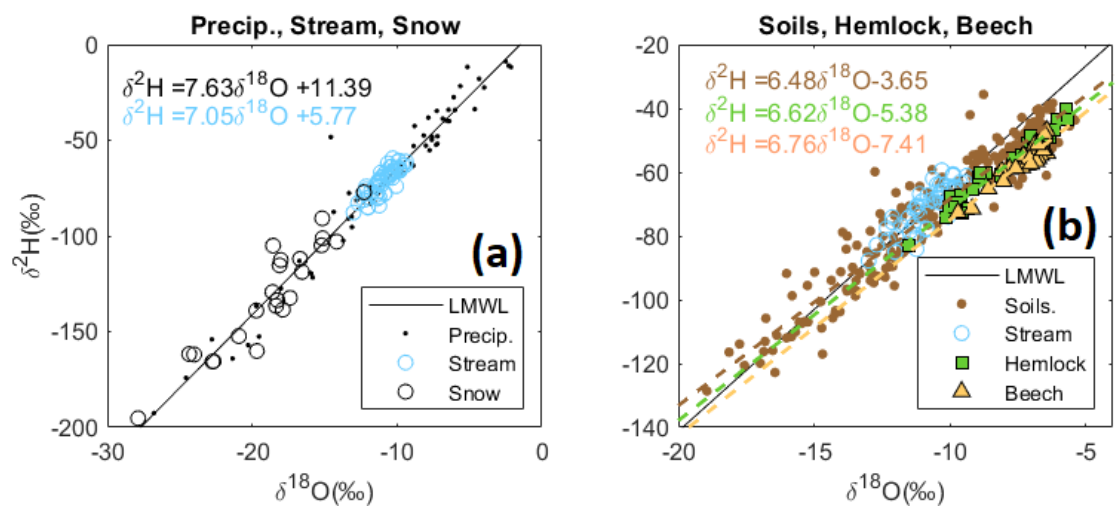

Figure 3 - Isotopic measurements made within the Hammond Hill Research Catchment for a) gross precipitation, stream water, and snowpack, and c) soils and xylem of hemlock and beech trees. 

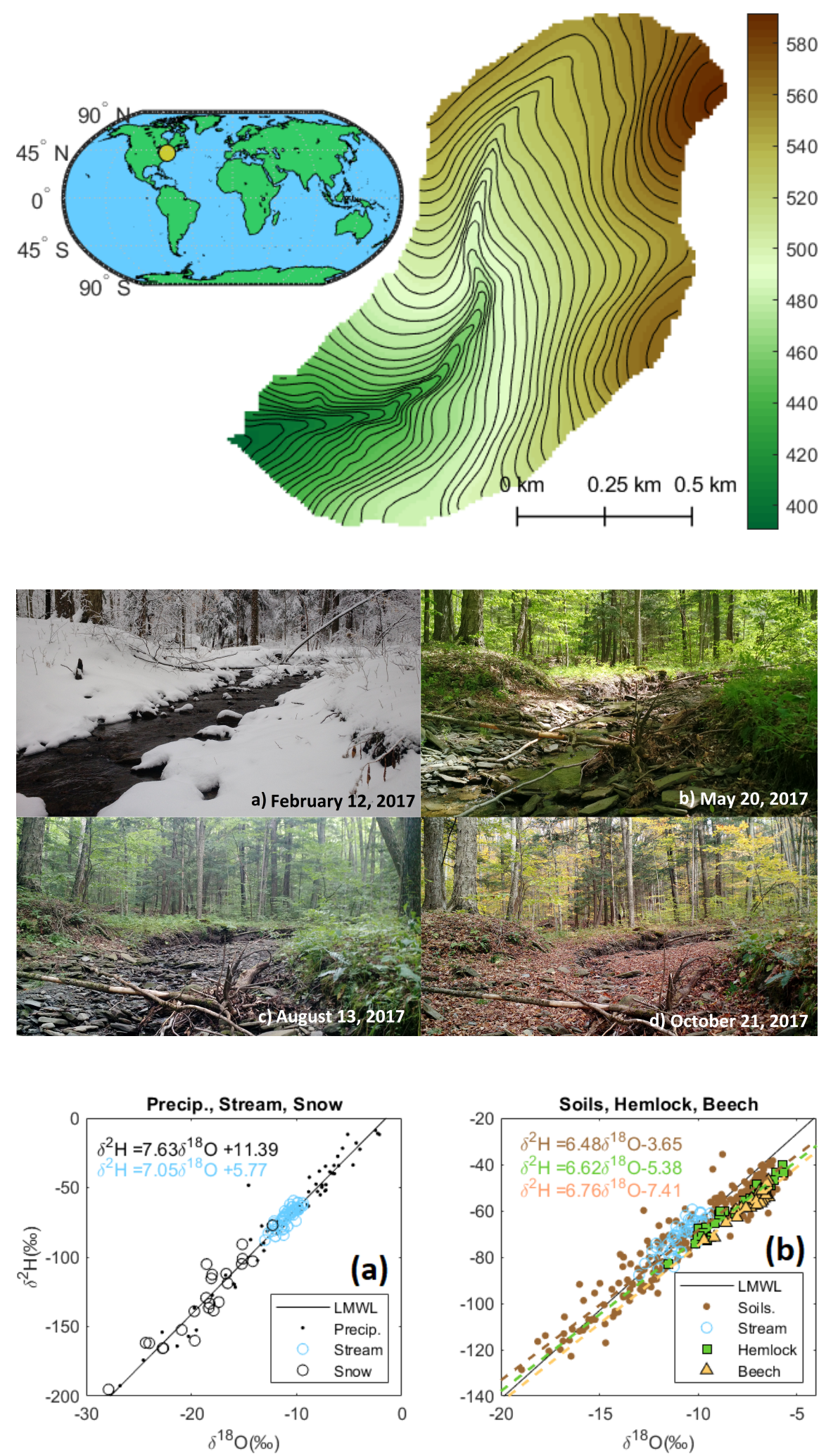